\title{
5
}

\section{A PEDAGOGIA HISTÓRICO-CRÍTICA E AS POSSIBILIDADES DE CONSTRUÇÃO DA ESCOLA ${ }^{* 1}$}

Marcos R. Lima

\section{Introdução}

O objetivo do presente capítulo é situar a PHC no âmbito da Concepção Histórico-Crítica da Educação, destacando seus fundamentos gramscianos. O caráter coletivo de sua elaboração evidencia o papel de organização da cultura assumido pelo conjunto de seus "militantes", conformando-se um intelectual coletivo que atua direta e intencionalmente no interior da reforma intelectual e moral propugnada pela filosofia da práxis na acepção gramsciana, colaborando para o desenvolvimento dos fundamentos da pedagogia socialista no Brasil ${ }^{2}$.

Como reconhece Saviani, em Pedagogia Histórico-Crítica, quadragésimo ano: novas aproximações (SAVIANI, 2019, p. 245), os pressupostos gramscianos se destacam na construção da PHC, sendo necessário o aprofundamento dessa fecunda interlocução. A partir da década de 1980, após 20 anos de ditadura civil-militar-empresarial, a questão da educação pública na perspectiva socialista pode ser sintetizada no confronto de dois posicionamentos distintos: a escola como aparelho privado de hegemonia, ancorado na análise gramsciana sobre a educação; e a escola como aparelho ideológico de Estado, fundamentado na elaboração teórica de Louis Althusser (DORE, 2006, p. 329). O primeiro posicionamento, da luta pela hegemonia popular no interior da escola, é defendido no interior da Concepção História-Crítica da Educação, que tem na PHC um momento significativo de ela-

\footnotetext{
${ }^{*}$ DOI - 10.29388/978-65-86678-91-8-0-f.107-128

${ }^{1}$ Versão revista da aula ministrada no curso Pedagogia Histórico-Crítica e prática transformadora, organizado pelo Grupo de Estudos e Pesquisas HISTEDBR, entre os dias 24/09/2020 e 14/01/2021; disponivel em: https://www.youtube.com/watch?v=rk5s2L_wGiU.

${ }^{2}$ Atualmente, desenvolvemos uma pesquisa de pós-doutorado intitulada: A tradutibilidade de Gramsci na educação brasileira: apontamentos pedagógicos para uma reforma intelectual e moral. O presente artigo apresenta resultados parciais da pesquisa em curso.
} 
boração, necessitando ser incorporada à prática político-pedagógica desenvolvida pelos aparelhos privados de hegemonia popular, sobretudo nas escolas públicas, em que se encontra a grande maioria das crianças, jovens e adultos oriundos da classe trabalhadora, com vistas a se organizar um verdadeiro educador coletivo, capaz de massificar a perspectiva socialista de organização do trabalho educativo.

Antes de desenvolvermos os fundamentos da escola unitária, num breve preâmbulo, resgataremos a problemática por nós desenvolvida no artigo A pedagogia histórico-crítica e a atualidade do trabalho como princípio educativo: apontamentos para a prática revolucionária na educação popular ${ }^{3}$, publicado em 2016, em que, ao criticarmos as reformas educacionais das últimas décadas, marcadas pela instrumentalização de categorias e conceitos caros ao marxismo como a categoria trabalho, ofuscando a compreensão dos conflitos sociais e sua ancoragem nas relações sociais de produção, reiteramos o princípio educativo do trabalho socialmente necessário e os fundamentos da escola unitária como instrumento de resistência ativa.

Ao ser manuseada de forma indevida pelos reformadores neoliberais, em termos pedagógicos a categoria trabalho foi reduzida à formação para o mercado de trabalho, por meio da aquisição de um conjunto de habilidades e competências que supostamente garantiriam a empregabilidade do trabalhador. Os conhecimentos técnico-científicos e humanísticos necessários à formação omnilateral dos indivíduos passaram a ser desqualificados, inviabilizando-se a compreensão das relações sociais de produção e da prática social global, resultando no aperfeiçoamento de estratégias de controle social que tendem a aprisionar os indivíduos na dinâmica da vida cotidiana. Com isso, diluiu-se a percepção dos conflitos sociais em um caleidoscópio de múltiplas identidades, passando a categoria de classe a ser entendida apenas como mais uma delas. Ao desmistificarmos o caráter utilitarista do conceito de trabalho no qual estão ancoradas as pedagogias liberais na atualidade, apontamos a necessidade de estratégias de articulação da educação às diferentes iniciativas populares de resistência à exploração capitalista, desaguando na proposição da escola unitária como referência para a organização do trabalho escolar na acepção socialista advogada pela PHC, articulando

\footnotetext{
${ }^{3}$ Revista HISTEDBR On-line, Campinas, no 67, p. 53-67, mar 2016; disponível em: https://periodicos.sbu.unicamp.br/ojs/index.php/histedbr/article/view/8646091/13284.
} 
como estratégia a organização de um Complexo Pedagógico HistóricoCrítico.

Tal eixo já havia sido por nós delineado em A Pedagogia-HistóricoCrítica como teoria pedagógica transformadora: da consciência filosófica à prática revolucionária (LIMA \& BATISTA, 2012). Neste artigo, após retomarmos as raízes da $\mathrm{PHC}$, destacando o seu empenho na superação tanto das pedagogias renovadoras, quanto das teorias críticoreprodutivistas, à guisa de conclusão afirmamos que, para além da valorização dos conteúdos escolares e da qualidade do ensino, a PHC se insere num movimento global de transformação social e superação da divisão capitalista do trabalho, alçando as jovens gerações ao patamar de dirigentes do processo de construção de uma nova civilização (LIMA \& BATISTA, 2012, p. 35). Não é o outro o sentido do seguinte excerto que extraímos do livro Pedagogia Histórico-Crítica: primeiras aproximações:

Se a educação é mediação no seio da prática social global, e se a humanidade se desenvolve historicamente ${ }^{4}$, isso significa que uma determinada geração herda da anterior um modo de produção com os respectivos meios de produção e relações de produção. $E$ a nova geração, por sua vez, impõe-se a tarefa de desenvolver e transformar as relações herdadas das gerações anteriores. Nesse sentido, ela é determinada pelas gerações anteriores e depende delas. Mas é uma determinação que não anula a sua iniciativa histórica, que se expressa justamente pelo desenvolvimento e pelas transformações que ela opera sobre a base das produções anteriores. À educação, na medida em que é mediação no seio da prática social global, cabe possibilitar que as novas gerações incorporem os elementos herdados de modo que se tornem agentes ativos no processo de desenvolvimento $e$ transformação das relações sociais (SAVIANI, 2012, p. 121 - grifos nossos).

\footnotetext{
${ }^{4} \mathrm{Na}$ obra A ideologia alemã, Marx e Engels sintetizam a concepção materialista da história, fundamento teórico-metodológico para compreendermos o lugar que a educação ocupa no seio da prática social global: "Essa concepção da história consiste [...] em desenvolver o processo real da produção a partir da produção material da vida imediata e em conceber a for ma de intercâmbio conectada a esse modo de produção e por ele engendrada, quer dizer, a sociedade civil em seus diferentes estágios, como fundamento de toda a história, tanto a apresentando em sua ação como estado como explicando a partir dela o conjunto das diferentes criações teóricas e formas da consciência - religião, filosofia, moral etc. - e em seguida o seu processo de nascimento a partir dessas criações, o que então torna possível, naturalmente, que a coisa seja apresentada em sua totalidade (assim como a ação recíproca entre esses diferentes aspectos)" (MARX \& ENGELS, 2007, p. 42).
} 
A relação entre educação e política aqui se destaca, como já havia apontado Saviani em Escola e democracia (SAVIANI, 2009). Desenvolvendose concomitantemente ao processo de transformação social e superação da ordem capitalista, a PHC tem por premissa a superação da divisão social do saber que caracteriza tal ordem, almejando instrumentalizar as camadas populares com as ferramentas de caráter teórico-prático das diferentes disciplinas escolares. Assevera Saviani:

Ora, em meu modo de entender, tal contribuição será tanto mais eficaz quanto mais o professor for capaz de compreender os vínculos da sua prática com a prática social global. Assim, a instrumentalização desenvolver-se-á como decorrência da problematização da prática social, atingindo o momento catártico que concorrerá na especificidade da matemática, da literatura etc., para alterar qualitativamente a prática de seus alunos como agentes sociais. Insisto neste ponto porque, em geral, há a tendência a desvincular os conteúdos específicos de cada disciplina das finalidades sociais mais amplas. Então, ou se pensa que os conteúdos valem por si mesmos sem necessidade de referi-los à prática social em que se inserem, ou se acredita que os conteúdos específicos não têm importância, colocando-se todo o peso na luta política mais ampla. Com isso dissolve se a especificidade da contribuição pedagógica, anulando-se, em consequência a sua importância política (SAVIANI, 2009, p. 72).

A construção da hegemonia popular passa necessariamente pelo desenvolvimento da capacidade dirigente das classes subalternas, concomitantemente ao processo de construção da sociedade civil popular e do Estado democrático-popular ${ }^{5}$, problemática que emerge no Brasil ao final da ditadura civil-militar (SEMERARO, 2009, p. 113), cujo enfrentamento resulta, ainda na transição para a década de 1980, na emergência da PHC como proposta no âmbito da educação pública, inserida

\footnotetext{
${ }^{5}$ Ao realizar no Cd. 25 apontamentos metodológicos para uma história dos grupos sociais su balternos, destaca Gramsci que: "A classes subalternas, por definição, não são unificadas e não podem se unificar enquanto não puderem se tornar "Estado" (GRAMSCl, 2002, vol. 5, p. 139). Em A questão meridional, observa Gramsci que "o proletariado é pobre de elementos organizativos" de massa. Só muito lentamente e de maneira trabalhosa após a conquista do poder estatal, sendo se grande valia os momentos de ruptura de caráter orgânica dos intelectuais em uma formação de massa orientada para ao proletariado revolucionário (tendência de esquerda) (GRAMSCI, 2004, vol. 2, p. 434).
} 
no contexto mais amplo de luta pela direção político-cultural da sociedade brasileira.

No artigo de 2016, citado anteriormente, após inserirmos a emergência da "pedagogia do aprender a aprender" no contexto da reestruturação produtiva do capital, enfatizamos a centralidade do princípio educativo do trabalho socialmente necessário, cujo caráter revolucionário, filosoficamente ancorado no materialismo históricodialético, é subvertido na pedagogia da experiência de Dewey, destituindoo da perspectiva histórica transformadora da escola unitária, defendida na conclusão do referido artigo.

Dewey criticava a pedagogia tradicional por defender a transmissão do passado às novas gerações, identificando-se o ato de aprender com aquisição do que foi incorporado aos livros e à cabeça das gerações anteriores, o que resultaria em um formato de ensino essencialmente estático, produzindo indivíduos dóceis, receptivos e obedientes. A esse modelo de ensino, Dewey contrapôs o que em Experiência e educação denominou de "educação progressiva". Segundo o autor, o esquema tradicional não respeita o alcance da experiência que o jovem aluno possui, o que resultaria na imposição de padrões, matérias de estudo, métodos de aprendizagem e comportamentos, cujos aspectos brutais seriam mascarados por artifícios utilizados pelos professores. A isso se opõe a educação nova, em que:

O cultivo e a expressão da individualidade se opõem à imposição de cima para baixo; a atividade livre se opõe à disciplina externa; aprender por experiência em oposição à aprendizagem através de textos e professores; a aquisição de habilidades e técnicas como meio para atingir fins que correspondem às necessidades diretas e vitais do aluno em oposição à sua aquisição através de exercício e treino; aproveitar ao máximo as oportunidades do presente se opõe à preparação para um futuro mais ou menos remoto; o contato com um mundo em constante processo de mudança em oposição a objetivos e materiais estáticos (DEWEY, 2011, p. 22).

A distância dos métodos ativos de Dewey em relação ao princípio pedagógico da proposta de organização do trabalho intelectual, apresentada por Gramsci no $\mathrm{Cd}$. 12, parágrafo 2: Observações sobre a 
escola: para a investigação do princípio educativo ${ }^{6}$ (GRAMSCl, 2004, vol. 2, p. 42), em que se encontram os fundamentos da escola unitária, é enorme, como veremos.

Tendo por fundamento pedagógico a escola unitária e o trabalho como princípio educativo, Gramsci enfrentou os desafios impostos pelo "americanismo", modelo mais desenvolvido da sociedade urbano industrial de sua época, buscando em suas contradições as possibilidades de superação da ordem capitalista, com sua divisão do trabalho fundamentada na propriedade privada dos meios de produção e na separação entre trabalho intelectual e manual, dirigentes e dirigidos, propugnando um "americanismo de novo tipo", "não americano", um americanismo "socialista" (MANACORDA, 2008, p. 288).

$\mathrm{Na}$ parte 1, Fundamentos gramscianos da Pedagogia HistóricoCrítica: a questão escolar no interior da reforma intelectual e moral, apresentamos elementos da interlocução entre a PHC e a teoria gramsciana da cultura, no interior da qual emerge a problemática da educação, como parte constitutiva da luta hegemônica entre as classes fundamentais, que originando-se na base econômica da sociedade, espalha-se por todas as dimensões da vida. A questão escolar é pensada no interior da reforma intelectual e moral da sociedade hodierna, emergindo de suas contradições a proposta de superação da crise escolar no seio da crise mais geral da sociedade capitalista.

$\mathrm{Na}$ parte 2, A escola unitária e as possibilidades de avanço da pedagogia socialista na construção do Complexo Pedagógico HistóricoCrítico, desenvolvemos os fundamentos da escola unitária, que, expressando em termos pedagógicos os interesses das classes subalternas, apresenta-se como instrumento de organização da cultura popular, desenvolvendo a capacidade dirigente e inserção das jovens gerações de trabalhadores na vida pública, subvertendo os fundamentos da sociedade civil liberal e o do aparelho estatal.

\footnotetext{
${ }^{6}$ A questão educacional aparece em diferentes passagens dos cadernos do cárcere, para além do $\mathrm{Cd}$. 12, destacamos o Cd. 11, em que a filosofia da práxis é apresentada por Gramsci como a grande reforma intelectual e moral de nossa época, expressando o ponto mais elevado da consciência filosófica de suas contradições históricas e a necessidade de sua superação, o que nos remete à questão escolar na perspectiva da escola unitária. Longe de propor uma alternativa idealista de organização do trabalho educativo, apresenta Gramsci uma tendência unitária de educação das massas que Lenin (GRAMSCI, 2006, vol. 1, p. 205) e krupskaya (KRUPSKAYA, 2017, p. 62) haviam captado.
} 
À guisa de conclusão, destacamos o conteúdo e a forma da escola na acepção histórico-crítica da educação, reiterando a defesa dos fundamentos da escola unitária na elaboração de um Complexo Pedagógico Histórico-Crítico a serviço das classes subalternas na construção de sua hegemonia, que, instrumentalizando-se para as tarefas de organização da nova sociedade, educam-se no processo de transformação da antiga ordem societária.

\section{Fundamentos gramscianos da Pedagogia Histórico-Crítica: a questão escolar no interior da reforma intelectual e moral}

Segundo Saviani, a presença de Gramsci na construção da PHC pode ser considerada de três maneiras: afinidade de propósitos entre a PHC e o empreendimento filosófico-teórico e político-prático gramsciano; aproximação de caráter metodológico, marcada pela adoção na PHC da mesma posição assumida por Gramsci diante do materialismo histórico-dialético; por fim, a incorporação à PHC das análises e categorias elaboradas por Gramsci (SAVIANI, 2020, p. 246). É sobretudo esse último aspecto que será aqui desenvolvido, inserindo-se a problemática da educação no interior da reforma intelectual e moral da civilização atual. Assim como Gramsci, Saviani desenvolve a problemática da educação no interior do tema geral do marxismo, a gênese, consolidação, desenvolvimento e as condições de crise da sociedade capitalista. Gramsci não toma a pedagogia como objeto, tarefa à qual se dedica Saviani, porém a educação ganha destaque no interior da elaboração gramsciana do Estado, como luta de hegemonias, o que em termos teórico-metodológicos enriquece a síntese pedagógica histórico-crítica deste último.

Apesar de não serem determinantes, as questões pedagógicas possuem uma dimensão estratégica na superação da ordem capitalista, sendo pensadas de maneira subversiva no interior mesmo dessa ordem, instrumento de organização da cultura no processo de construção da hegemonia popular. Distante de qualquer lampejo determinista, os proponentes da PHC entendem que a velha ordem não perecerá e o Estado não definhará sem a intervenção consciente dos construtores da nova ordem, impulsionados intelectual e moralmente pelos fundamentos da filosofia da práxis, traduzidos em termos pedagógicos pela PHC.

Gramsci critica (DORE, 2006, p. 337) a leitura determinista do vínculo entre estrutura e superestrutura, destacando a importância da 
educação e da dimensão cultural, a partir da análise do Prefácio de 1859, de Marx, desaguando no conceito de bloco histórico. No Prefácio à Contribuição à crítica da Economia Política, diz Marx:

Em uma certa etapa de seu desenvolvimento, as forças produtivas materiais da sociedade entram em contradição com as relações de produção existentes ou, o que nada mais é do que a sua expressão jurídica, com as relações de propriedade dentro das quais aquelas até então se tinham movido. De formas de desenvolvimento das forças produtivas essas relações se transformam em seus grilhões. Sobrevém então uma época de revolução social. Com a transformação da base econômica, toda a enorme superestrutura se transforma com maior ou menor rapidez. Na consideração de tais transformações é necessário distinguir sempre entre a transformação material das condições econômicas de produção, que pode ser objeto de rigorosa verificação da ciência natural, e as formas jurídicas, políticas, religiosas, artísticas ou filosóficas, em resumo, as formas ideológicas pelas quais os homens tomam consciência desse conflito e o conduzem até o fim (MARX, 1996, p. 52).

Na luta pela hegemonia entre a velha e a nova ordem societária, é preciso se considerar o grau de realismo das diferentes ideologias em disputa, entendidas como a maneira como os indivíduos tomam consciência dos conflitos sociais e elaboram suas estratégias de enfrentamento. Portanto, a estrutura objetiva é a "realidade rebelde" que incide diretamente sobre os diferentes grupos e projetos sociais em luta (GRAMSCl, 2007, vol. 3, p. 40). Coloca-se a questão do Estado, entendido como instrumento para a adequação da sociedade à estrutura econômica em transformação (idem, 2006a, vol. 1, p. 324). Desde que, é claro, a classe que se faz dirigente queira sepultar com todas as honras o velho homo economicus (ibidem).

Longe de entender a estrutura como um "deus oculto" que determina de maneira mecânica a superestrutura e, por consequência, a cultura de uma determinada sociedade, no seio da qual se encontram as diferentes formas de organização do trabalho educativo, adverte Gramsci que a estrutura deve ser entendida como a "realidade em movimento", unidade dialética ou relação recíproca entre os elementos da estrutura e da superestrutura, conformando-se um bloco histórico. Resgatando as teses sobre Feuerbach (tese III) questiona Gramsci se a afirmação de que o 
"educador deve ser educado" não evidenciaria uma relação necessária de reação ativa do homem sobre a estrutura, unidade do processo do real ${ }^{7}$ (ibidem, p. 370).

Ganha relevo a luta cultural e o "momento cultural" na atividade prática ou coletiva dos homens ${ }^{8}$, buscando-se, por intermédio da filosofia da práxis, concepção de mundo unitária, a unidade "cultural-social" necessária para impulsionar as transformações históricas, coincidindo a transformação dos indivíduos com a transformação mesma das circunstâncias que os formam. Uma relação dialética cujo caráter pedagógico extrapola o espaço "escolar", permeando toda a sociedade no seu conjunto e todo o indivíduo em sua relação com os demais, a relação entre camadas intelectuais e não intelectuais, governantes e governados, elites e seguidores, entre dirigentes dirigidos, entre vanguardas e corpos de exército, nacional e internacionalmente, entre nações e civilizações". Assim, conclui Gramsci que "toda relação de hegemonia é necessariamente uma relação pedagógica" (GRAMSCl, 2006a, vol. 1, p. 399). Destaca-se a seguinte síntese, de valor teórico-metodológico para a compreensão da relação entre educação e hegemonia no interior da teoria gramsciana:

Transformar o mundo exterior, as relações gerais, significa fortalecer a si mesmo, desenvolver a si mesmo. É uma ilusão e um erro supor que o "melhoramento" ético seja puramente individual: a síntese dos elementos constitutivos da individualidade é "individual", mas ela não se realiza e desenvolve sem uma atividade para fora transformadora das relações externas, desde aquelas com a natureza e com os outros homens em vários níveis, nos diversos círculos em que se vive,

\footnotetext{
${ }^{7}$ Conclui Gramsci que o homem deve ser concebido como um bloco histórico, composto de elementos subjetivos, individuais e de massa, e materiais ou objetivos, com os quais interage ativamente. Portanto, o homem é vontade concreta, incidindo o seu "impulso vital" sobre os meios para a concretização de seus projetos (GRAMSCl, 2006a, vol. 1, p. 406).

${ }^{8}$ No parágrafo 17 do $\mathrm{Cd}$. 10, ao introduzir elementos metodológicos para o estudo da filosofia, Gramsci nos apresenta uma acepção em bloco da filosofia e da história: "[...] história da filosofia tal como é comumente entendida isto é, como história das filosofias dos filósofos, é a história das tentativas e das iniciativas ideológicas de uma determinada classe de pessoas para mudar, corrigir, aperfeiçoar as concepções do mundo existentes em todas as épocas determinadas e para mudar, portanto, normas de conduta que lhes são coletivas são relativas e adequadas, ou seja, para mudar a atividade prática em seu conjunto" (GRAMSCI, 2006a, vol. 1, p. 325). "História integral, concreta e completa", conclui Gramsci (ibidem, p, 326).
} 
até relação máxima, que abarca todo o gênero humano. Por isso, é possível dizer que o homem é essencialmente "político", já que a atividade para transformar e dirigir conscientemente os outros homens realiza a sua "humanidade", a sua "natureza humana" (GRAMSCl, 2006a, vol. 1, p. 407).

Aqui chegamos ao ponto culminante da problemática anunciada no Cd. 11, se seria preferível manter-se preso a formas de pensamento desagregadas e ocasionais, aceitando-se passivamente uma concepção de mundo imposta mecanicamente do ambiente exterior, ou se, por outro lado, seria preferível elaborar conscientemente, de maneira crítica, a própria concepção de mundo, participando ativamente na produção da história, tornando-se "guia de si mesmo"? (ibidem, p. 94).

É preciso instrumentalizar a cada indivíduo singular para que possa se inserir de maneira crítica na coletividade, na vida pública. O ponto de partida é conhecimento daquilo que nos trouxe até aqui, um processo pedagógico de crítica à concepção de mundo que trazemos conosco, tornando-a "unitária e coerente", até o ponto em que o grau mais elevado atingido pelo pensamento mundial seja assimilado, realizando-se um inventário crítico de toda filosofia que ganhou relevo como síntese da luta pela hegemonia em diferentes épocas, deixando marcas na filosofia popular. Assim, para Gramsci, o: "[...] início da elaboração crítica e a consciência daquilo que é realmente, isto é, um "conhece-te a ti mesmo"

\footnotetext{
${ }^{9}$ No artigo datado de 29 de janeiro de 1916, intitulado Socialismo e cultura, Gramsci resgata de Novalis a seguinte passagem: "[...] O supremo problema da cultura é de dominar o próprio eu transcendental, de ser ao mesmo tempo o eu do próprio eu. Por isso, surpreende pouco a falta de intuição e de conhecimento completo dos outros. Sem uma perfeita compreensão de nós mesmos, não poderemos compreender verdadeiramente os outros". De Vico, Gramsci resgata o dito de Sólon, assumido por Sócrates para a filosofia: "Conhece-te a ti mesmo." Vico afirma que Sólon, com este dito, quis aconselhar os plebeus, que acreditavam ser de origem bestial, enquanto os nobres seriam de origem divina, a refletirem sobre si mesmos para se reconhecerem de igual natureza humana que os nobres e, por conseguinte, para pretenderem ser-lhes igualados no direito civil. E, em seguida, põe essa consciência da igualdade humana entre plebeus e nobres como a base e a razão histórica do surgimento das repúblicas democráticas na Antiguidade (GRAMSCI, 2004, p. 56ss). Destaca-se na elaboração gramsciana o espírito de ruptura, conquista progressiva da consciência da própria personalidade histórica, resultando em iniciativas de desconstrução-recriação da sociedade, participando-se ativamente da disputa de projetos ético-políticos, atingindo-se a catarse, momento em que a transformação das estruturas econômicas e do aparelho do Estado, as sim como das relações sociais e intersubjetivas, entrecruzam-se dialeticamente no processo de construção da hegemonia popular (SEMERARO, 2009, p. 178).
} 
como produto do processo histórico até hoje desenvolvido, que deixou em ti uma infinidade de traços acolhidos sem análise crítica" (ibidem).

Como podemos notar, as pretensões da filosofia da práxis são elevadas. Superar a separação entre cultura moderna e cultura popular ou folclore, disseminando-se no seio das massas populares uma concepção de mundo coerente e unitária. Uma atividade deste gênero, feita em profundidade, corresponderia no plano intelectual ao que foi a Reforma nos países protestantes, assevera Gramsci (GRAMSCI, 2002b, vol. 6, p. 136).

Como a grande reforma intelectual e moral de nossa época, a filosofia da práxis não pode correr o risco de se perder em desvios intelectualistas na formação dos novos intelectuais, cujo resultado são indivíduos pedantes isolados nas cátedras das universidades. Como alerta Gramsci, os intelectuais têm a função de determinar e organizar a reforma moral e intelectual da sociedade, adequando a cultura das massas a uma função prática (GRAMSCl, 2006a, vol. 1, p. 126), processo no qual se corre o risco de que a reforma se restrinja a alguns nichos intelectuais, não atingindo as massas. Caso isso ocorra, seus avanços podem ser desagregados à primeira contraofensiva (ibidem, p. 233). Conclui Gramsci que:

Não é possível pensar na vida e na difusão de uma filosofia que não seja simultaneamente política atual, estreitamente ligada à atividade preponderante na vida das classes populares, o trabalho, e que não se apresente, por tanto, dentro de certos limites, como necessariamente vinculada à ciência. Essa nova concepção talvez assuma inicialmente formas supersticiosas e primitivas como as da religião mitológica, mas encontrará em si mesma e nas forças intelectuais que o povo extrairá de seu seio os elementos para superar esta fase primitiva. Esta concepção vincula o homem à natureza por meio da técnica, mantendo a superioridade do homem e exaltando-a no trabalho criador; portanto, exalta o espírito e a história (ibidem, p. 365).

Para a Concepção Histórico-Crítica da Educação a pedagogia socialista deve ser desenvolvida na transição ao novo modo de produção, como instrumento pedagógico no do processo de reforma intelectual e moral da sociedade, permeando a elaboração, sistematização, execução e gestão dos projetos societários da nova ordem a ser edificada. Especular sobre o formato de uma CHCE numa sociedade socialista do "futuro" nos leva ao equívoco idealista de pensar que a força das ideias pode 
desarticulá-las da realidade rebelde que as condiciona. A CHCE é definida em termos históricos, assim como o próprio ser humano, sendo, portanto, um dado concreto. Uma pedagogia do homem no processo de emancipação e humanização, subsidiando a superação dos entraves à constituição do homem integral. Como possível estratégia político-pedagógica no processo de transição socialista, emerge a proposta gramsciana da escola unitária, cujos fundamentos apresentaremos a seguir.

\section{A escola unitária e as possibilidades de avanço da pedagogia socialista na construção do Complexo Pedagógico Histórico-Crítico}

Como vimos no item anterior, a cultura para Gramsci é "organização da vida", tendo como ponto de partida a produção material sobre a qual se elevam os elementos superestruturais, dentre os quais a educação escolar. Da crítica da economia política, emerge o socialismo como estratégia para a superação da velha ordem capitalista. $O$ que não pode ser interpretado como algo para o futuro, implicando na emergência de novas relações sociais ainda no contexto de hegemonia do capital. Tratase, portanto, da criação de uma nova cultura integral, ancorada numa nova concepção de mundo, a filosofia da práxis, que longe de ceder aos desvios positivistas, propõe uma integral reforma intelectual e moral, no seio da qual se encontra o problema da educação, compreendida como "organização da cultura", destacando-se em seu seio a organização da escola unitária, propondo uma nova relação entre o trabalho intelectual e o trabalho industrial, para além do espaço escolar, estendendo-se por toda a vida social (GRAMSCI, 2006b, vol. 2, p. 40).

É papel da escola superar o folclore e todas as sedimentações tradicionais de concepções de mundo, difundindo o ponto mais elevado atingido pela cultura mundial. É preciso difundir uma concepção mais moderna de mundo, destacando-se a aprendizagem das "leis naturais", como vimos anteriormente, como algo "objetivo e rebelde", para assim dominá-las, por meio do trabalho. Juntamente com as "leis civis e estatais", adquirindo uma intuição historicista do mundo e da vida ${ }^{10}$, entendendo-as como:

\footnotetext{
${ }^{10}$ A concepção dialética, histórica do mundo, elemento dinamizador do currículo escolar, permeando todo o saber elaborado a ser transmitido às jovens gerações tem por ponta de partida essa "intuição liberta de todo elemento de toda magia ou bruxaria" (GRAMSCI, 2006b, vol. 2, p. 43).
} 
[...] produto de uma atividade humana, que são estabelecidas pelo homem e podem ser por ele modificadas tendo em vista seu desenvolvimento coletivo; a lei civil e estatal organiza os homens do modo historicamente mais adequado dominar as leis da natureza, isto é, a tornar mais fácil o seu trabalho, que é a forma própria através da qual o homem participa ativamente na vida da natureza, visando a transformá-la e socializá-la cada vez mais profunda e extensamente. Pode-se dizer, por isso, que o princípio educativo no qual se baseavam as escolas primárias era o conceito de trabalho, que não pode se realizar em todo seu poder de expansão e de produtividade sem um conhecimento exato e realista das leis naturais e sem uma ordem legal que regule organicamente a vida dos homens entre si, ordem que deve ser respeitada por convicção espontânea e não apenas por imposição externa, por necessidade reconhecida e proposta a si mesmo como liberdade e não por simples coerção (GRAMSCl, 2006b, vol. 2, p. 42-43).

Destaca-se aqui o princípio educativo do trabalho, amálgama entre a proposta da escola unitária e a concepção, também unitária, de sociedade defendida por Gramsci, que tem por base a reforma industrial democrática, devendo a reforma cultural estar articulada a um programa de reforma econômica (GRAMSCl, 2007, vol. 3, p. 19).

O que nos remete ao conceito de civilização ou humanidade, pensado por Gramsci como síntese da luta pela hegemonia, o novo e o velho numa intensa batalha pela conformação do consenso, pela transformação da necessidade de coerção em um ato espontâneo, conformismo ativo. É nessa perspectiva histórica que entendemos o surgimento da educação moderna, que surge da necessidade de se construir instrumentos de massificação da ordem liberal, então revolucionária, incorporando ao âmbito do modo de vida burguês as classes sociais que antagonizavam com as forças da conservação do Antigo Regime.

O ponto culminante desse processo é a emergência do anarquismo, do socialismo e do comunismo, enquanto crítica ao modo de vida burguês, cuja vertente materialista histórico-dialética fundamenta a Concepção Histórica-Crítica da Educação, inaugurada por Marx e Engels, subvertendo as promessas libertárias das revoluções burguesas, sobretudo no âmbito da educação. Anuncia-se a aurora da República do trabalho livremente associado, fundamentada em termos pedagógicos no princípio educativo do trabalho na formação das jovens gerações, capacitando-as para a 
inserção na vida pública e a direção consciente da sociedade. É esse o fundamento pedagógico da filosofia da práxis, que se torna a reforma intelectual e moral de nossa época. Ao defendermos a produção direta e intencional em cada indivíduo singular da humanidade produzida historicamente pelo conjunto da humanidade, pressuposto do trabalho educativo na acepção histórico-crítica (SAVIANI, 2012, p. 13), inserimos a proposta da escola unitária no contexto de transição que se abre a partir da emergência do projeto comunista de sociedade, horizonte do desenvolvimento consciente da história futura da humanidade.

Gramsci desenvolveu os fundamentos da escola unitária no interior do projeto de estudos intitulado (Cd. 12) Apontamentos e notas dispersas para um grupo de ensaios sobre a história dos intelectuais, ponto de partida para a produção de ensaios de história da cultura e de história política. Longe da ideia de intelectuais supostamente autônomos em relação à base econômica e a luta de classes, Gramsci entende os intelectuais como uma categoria determinada historicamente, vinculando-se a determinados grupos sociais situados no mundo da produção e as relações sociais que o caracterizam. No contexto de transição, tornam-se orgânicos aqueles intelectuais partícipes de determinado projeto societário, que assumem o papel de organizadores de todo o complexo econômico, social, político e, por que não, pedagógico, que o conforma, almejando incorporar parte dos intelectuais (tradicionais) da velha ordem, que, pelo espírito de grupo, julgam-se autônomos, independente (GRAMSCI, 2006b, vol. 2, p. 17).

Diferentemente dessa intelectualidade que se mantém à margem da disputa pelo poder, o intelectual que advoga como fundamento teóricometodológico a PHC deve assumir a tarefa consciente de construção de uma nova civilização, ancorada numa nova visão de mundo, colaborando incansavelmente na tarefa de organização cultural das massas populares, em sua dimensão intelectual e moral, alçando-as à capacidade dirigente, por meio do trabalho pedagógico direta e intencionalmente articulado ao processo de transformação social e consolidação de uma sociedade integral, civil e política (ibidem, p. 24). Em síntese, enfrentando a questão do Estado, o intelectual-militante torna-se orgânico à massa popular, elaborando os quadros da nova civiltà.

É preciso pensar o fenômeno educativo e o papel da escola no interior da prática social global. Ao se abrir uma época de revolução social (MARX, 1996, p. 52), os fundamentos da sociedade são abalados, tencionando-se também as bases da antiga escola. Assim, a crise do 
programa e da organização da escola se insere no contexto mais amplo e geral de crise orgânica (GRAMSCl, 2006b, vol. 2, p. 33) que se instaura. Uma escola adequada aos fundamentos do novo princípio educativo das sociedades industriais modernas, em que a ciência se articula cada vez mais à vida cotidiana dos indivíduos, torna-se fundamental para alçá-los ao nível de desenvolvimento intelectual e moral mais elevado e integrar as competências para atividades manuais e intelectuais, no âmbito da sociedade civil e política, permitindo-lhes assumir a postura dirigente nos espaços da produção material e gestão da vida pública. A esta tarefa se presta a escola unitária, fundamentada no princípio educativo do trabalho socialmente necessário e coletivamente planejado por produtores livremente associados.

Ocorre que na luta pela manutenção de sua hegemonia as classes dominantes forjam instrumentos de organização de atividade "escolar" (em sentido lato) para elaboração dos quadros intelectuais que atuarão em diferentes espaços da sociedade. Gramsci compara o processo de organização da cultura em geral à esfera da técnica industrial ${ }^{11}$. Conformase a seguinte estrutura hierárquica da educação liberal. Por um lado, a escola profissional, destinada às classes instrumentais, por outro, a escola clássica (tradicional), fundamentada na tradição greco-romana, destinada às classes dominantes e intelectuais. Com o desenvolvimento social de base industrial, impõe-se às massas populares uma orientação técnicoprofissional, restringindo-se a formação humanística geral a uma elite não pressionada diretamente pela necessidade do trabalho. Eis o dilema pedagógico que marca a crise do programa e da organização escolar à época de Gramsci, cuja solução é apresentada nos seguintes termos:

A crise terá uma solução que, racionalmente, deveria seguir esta linha: escola única inicial de cultura geral, formativa, que equilibre de modo justo o desenvolvimento da capacidade de trabalhar manualmente (tecnicamente, industrialmente) e o desenvolvimento das capacidades de trabalho intelectual. Deste tipo de escola única, através

\footnotetext{
${ }^{11}$ Assim como Marx e Engels, Gramsci entende a indústria como um conjunto de atividades técnicas e relações sociais que extrapolam o chão da fábrica, espalhando-se por todos os espaços da sociabilidade. Trata-se do processo de racionalização das superestruturas a partir das transformações estruturais (GRAMSCl, 2007, vol. 4, p. 247-248). Assim, as questões pedagógicas são pensadas em sua relação com o mundo da produção material, criando-se complexos produtivos e pedagógicos dirigidos pelos "empresários", elaboração social superior marcada pela capacidade dirigente e técnica (GRAMSCl, 2006a, vol. 2, p. 15).
} 
de repetidas experiências de orientação profissional, passar-se-á a uma das escolas especializadas ou ao trabalho produtivo (GRAMSCl, 2006b, vol. 2, p. 33-34).

Gramsci tem em vista a formação de um intelectual de novo tipo, capaz de articular a técnica política e as tarefas administrativas no âmbito das atividades práticas essenciais das sociedades modernas ${ }^{12}$. Não se trata de um tipo ideal de intelectual, mas sim de um intelectual historicamente situado, que adequado às transformações estruturais de sua época se torna contemporâneo aos problemas que lhe são pertinentes. Isso porque, como observa Gramsci, o tipo tradicional do dirigente político, limitado a atividades jurídico-formais tornou-se anacrônico (ibidem, p. 35).

À guisa de síntese, destacamos aqui um princípio metodológico da escola unitária, caracterizada pelo caráter orgânico de sua estruturação. 0 processo de "escolarização da vida prática" por meio de um Complexo Pedagógico Histórico-Crítico que tende a desenvolver trabalhos orgânicos de conjunto, fundamentados na educação recíproca dos quadros intelectuais, gradativamente preparados para atividades deliberativas e técnico-culturais pertinentes à organização do Estado e participação na vida pública. Em termos didático-pedagógicos, em alusão à organização prática da vida urbano-industrial, propõe Gramsci a criação de estratégias de organização da cultura nacional-popular sintetizadas na metáfora da taylorização do trabalho intelectual:

Indubitavelmente, nesta espécie de atividade coletiva, cada trabalho produz novas capacidades e possibilidades de trabalho, já que cria condições de trabalho cada vez mais orgânicas: fichários, elencos bibliográficos, coletâneas de obras fundamentais especializadas etc. Exige-se uma luta rigorosa contra os hábitos do diletantismo, da improvisação, das soluções "oratórias" e declamatórias, O trabalho deve ser feito sobretudo por escrito, assim como por escrito devem ser as críticas, em notas resumidas e sucintas, o que pode ser obtido mediante a distribuição a tempo do material etc.; escrever as notas e

\footnotetext{
${ }^{12}$ Como síntese do homem moderno, em carta a Julia, de 1 de agosto de 1932, Gramsci assevera que: "O homem moderno deveria ser uma síntese daquelas características que são... hipostasiadas como características nacionais: engenheiro americano, o filósofo alemão, o político francês, recriando, por assim dizer, o homem italiano do Renascimento, o tipo moderno de Leonardo da Vinci transformado em homem massa ou homem coletivo, ainda que mantendo sua forte personalidade e originalidade individual" (GRAMSCl, 2005, vol. 2, p. 225).
} 
as críticas é princípio educativo didático que se tornou necessário graças à obrigação de combater os hábitos da prolixidade, da declamação e do paralogismo criados pela oratória. Este tipo de trabalho intelectual é necessário a fim de fazer com que os autodidatas adquiram a disciplina dos estudos proporcionada por uma carreira escolar regular, a fim de taylorizar o trabalho intelectual (GRAMSCI, 2006b, vol. 2, p. 35-36).

Na linha apontada anteriormente, a formação humanista, ou de cultura geral, desaparece a distância entre o saber erudito e o saber popular, cultura moderna e cultura popular, que passam a ser articulados em uma nova cultura ancorada na consciência filosófica e sua crítica ao senso comum, instrumentalizando as classes subalternas para que possam expressar de maneira elaborada seus interesses e organizarem-se enquanto classe (SAVIANI, 2009, p. 3) no processo de construção da hegemonia popular. O que pressupõe em termos metodológicos:

[...] desarticular dos interesses dominantes aqueles elementos que estão articulados em torno deles, mas não são inerentes à ideologia dominante e rearticulá-los em torno dos interesses populares, dando-Ihes a consistência, a coesão e a coerência de uma concepção de mundo elaborada, vale dizer, de uma filosofia (ibidem).

Aqui retomamos um excerto do $\mathrm{Cd}$. 11, Introdução ao estudo da filosofia, citado de passagem anteriormente, caro à elaboração teórica realizada por Saviani em Educação: do senso comum à consciência filosófica (SAVIANI, 2009, p. 8). Reagindo à ordem jesuítica e seu caráter pedagógico, marcado pela tentativa de manter na passividade as massas de fiéis, sentencia Gramsci:

A filosofia da práxis é antitética a esta posição católica: a filosofia da práxis não busca manter os "simples" na sua filosofia primitiva do senso comum, mas busca, ao contrário, conduzi-los a uma concepção de vida superior. Se ela afirma a exigência do contato entre os intelectuais e os simples não é para limitar a atividade científica e para manter uma unidade no nível inferior das massas, mas justamente para forjar um bloco intelectual-moral que torne politicamente possível um progresso intelectual de massa e não apenas de pequenos grupos intelectuais (GRAMSCl, 2006a, vol. 1, p. 103). 
Na crítica à escola tradicional e sua crise, conclui Gramsci que seu caráter oligárquico se encontra no fato de se restringir à formação de poucos indivíduos da nova geração, destinados a tornarem-se dirigentes. Entende Gramsci que a marca social da escola não está em formar "homens superiores", mas sim em manter a dicotomia entre a formação para funções dirigentes, por um lado, e instrumentais, por outro. A superação do caráter elitista da escola se encontra na organização de um tipo único de escola preparatória primário-média, capaz de formar as novas gerações de maneira omnilateral, capacitando-as não somente para as escolhas profissionais, formando-as para pensar, estudar e, sobretudo, dirigir e controlar quem exerce a função dirigente (GRAMSCl, 2006b, p. 49).

\section{Conclusão}

À guisa de conclusão, reiteramos o status da educação no interior do materialismo histórico-dialético, reforma intelectual e moral de nossa época, credenciando-se a PHC, ancorada no princípio educativo do trabalho no interior da proposta da escola unitária, como instrumento pedagógico para a elaboração em massa dos construtores de uma nova ordem societária para além do capital. No interior da Concepção Histórico-Crítica da Educação, emerge a PHC como síntese pedagógica do processo de organização da cultura e elaboração direta e intencional da nova sociedade, articulando estrategicamente a dimensão educativa das tarefas de organização popular à dimensão político-organizativa do trabalho educativo, forjando-se uma concepção integral e orgânica de educação, incidindo sobre o conteúdo e a forma da escola hodierna, inserida conscientemente na prática social global.

Nesse processo de luta pela hegemonia, inspirada nos fundamentos da escola unitária emerge a proposta de organização de um Complexo Pedagógico Histórico-Crítico, articulando os diferentes aparelhos privados de hegemonia popular em torno de um sistema orgânico de educação das massas, capaz de incorporar à luta em defesa da educação pública as iniciativas populares de organização da cultura, inseridas em seu conteúdo as tarefas de socialização da política, no interior da vida pública, do conhecimento técnico-científico, necessário ao domínio da natureza e da produção material da vida, e do conhecimento humanístico fundamental para a compreensão do que nos trouxe até aqui, forjando uma intuição historicista do mundo e da vida (GRAMSCl, 2006b, p. 48), para além dos 
muros do tradicional espaço escolar, "escolarizando", assim, todo o complexo educativo que permeia a vida em sociedade.

Superando a desarticulação entre o Homo sapiens e o Homo faber, entre o saber e o fazer, a PHC tem por horizonte não somente a qualificação do trabalhador manual, mas a emergência do "cidadão governante" (ibidem, p. 50), subvertendo as bases do Estado burguês, consolidando-se, assim, os fundamentos pedagógicos da sociedade regulada para cuja construção dedicou Gramsci a sua vida, inspirando aqueles que advogam a PHC como instrumento de elaboração em massa do novo homem e da nova mulher, construtores da civiltà futura.

\section{Referências}

DEWEY, John. Experiência e educação. 2a edição. Petrópolis-RJ: Editora Vozes, 2011.

DORE, Rosemary. Gramsci e o debate sobre a escola pública no Brasil.

Caderno Cedes, Campinas, vol. 26, n. 70, set./dez. 2006, [p. 329-352].

Disponível em:

https://www.scielo.br/j/ccedes/a/JQqvjsTwVfGYnTvZyq3N3Kf/?

format=pdf\&lang=pt

GRAMSCl, Antonio. Escritos políticos (vol. 1). 1910-1920. Socialismo e cultura. Rio de Janeiro: Civilização Brasileira, 2004a.

GRAMSCl, Antonio. (vol. 2). 1921-1926. A questão meridional. Rio de Janeiro: Civilização Brasileira, 2004b.

GRAMSCI, Antonio. Cartas do cárcere. (vol. 1). 1926-1930. Rio de Janeiro: Civilização Brasileira, 2005a.

GRAMSCl, Antonio. Cartas do cárcere. (vol. 2). 1931-1937. Rio de Janeiro: Civilização Brasileira, 2005b.

GRAMSCl, Antonio. Cadernos do cárcere (vol. 1). Introdução ao estudo da filosofia. A filosofia de Benedetto Croce. Rio de Janeiro: Civilização Brasileira, 2006a.

GRAMSCl, Antonio. (vol. 2). Os intelectuais. O princípio educativo. Jornalismo. Rio de Janeiro: Civilização Brasileira, 2006b. 
GRAMSCl, Antonio. (vol. 3). Maquiavel. Notas sobre o Estado e a política. Rio de Janeiro: Civilização Brasileira, 2007a.

GRAMSCl, Antonio. (vol. 4). Temas de cultura. Ação católica. Americanismo e fordismo. Rio de Janeiro: Civilização Brasileira, 2007b.

GRAMSCl, Antonio. (vol. 5). O Risorgimento. Notas sobre a história da Itália. Rio de Janeiro: Civilização Brasileira, 2002a.

GRAMSCl, Antonio. (vol. 6). Literatura. Folclore. Gramática. Rio de Janeiro: Civilização Brasileira, 2002b.

KRUPSKAYA, N. K. A construção da pedagogia socialista. São Paulo: Expressão popular, 2017.

LIMA, Marcos R. A pedagogia histórico-crítica e a atualidade do trabalho como princípio educativo: apontamentos para a prática revolucionária na educação popular. Revista HISTEDBR On-line, Campinas, no 67, p. 53-67, mar. 2016; disponível em:

https://periodicos.sbu.unicamp.br/ojs/index.php/histedbr/article/view/ $8646091 / 13284$

LIMA, Marcos R.; BATISTA, Eraldo L. A Pedagogia-Histórico-Crítica como teoria pedagógica transformadora: da consciência filosófica à prática revolucionária. In: BATISTA, E. L.; MARSIGLIA, A. C. G. (orgs.). Pedagogia Histórico-Crítica: desafios e perspectivas para uma educação transformadora. Campinas: Autores Associados, 2012.

MANACORDA, M. A. Gramsci: americanismo e conformismo. Campinas-SP: Alínea, 2008.

MARX, Karl. Prefácio à Contribuição à crítica da Economia Política. In: Marx. Os pensadores. São Paulo: Nova Cultural, 1996.

MARX, Karl; ENGELS, Friedrich. A ideologia alemã. São Paulo: Boitempo, 2007.

SAVIANI, Dermeval. Educação: do senso comum à consciência filosófica. 18a edição revista. Campinas-SP: Autores Associados, 2009a.

SAVIANI, Dermeval. Escola e democracia. 41ạ edição revista. Campinas-SP: Autores Associados, 2009b.

SAVIANI, Dermeval. Pedagogia Histórico-Crítica: primeiras aproximações. 11a edição revista. Campinas-SP: Autores Associados, 2012. 
SAVIANI, Dermeval. Pedagogia Histórico-Crítica, quadragésimo ano: novas aproximações. Campinas-SP: Autores Associados, 2019.

SAVIANI, Dermeval. SEMERARO, Giovanni. Libertação e hegemonia: realizar a América Latina pelos movimentos populares. Aparecida-SP: Ideias \& Letras, 2009. 